\title{
Timing of Vote Decision in First and Second Order Dutch Elections 1978-1995: Evidence from Artificial Neural Networks
}

\author{
Rob Eisinga \\ Department of Social Science Research Methods, University of Nijmegen \\ Philip Hans Franses \\ Rotterdam Institute for Business Economic Studies and \\ Econometric Institute, Erasmus University Rotterdam \\ Dick van Dijk* \\ Tinbergen Institute, Erasmus University Rotterdam
}

July 11, 1997

\begin{abstract}
A time series $(t=921)$ of weekly survey data on vote intentions in the Netherlands for the period 1978-1995 shows that the percentage of undecided voters follows a cyclical pattern over the election calendar. The otherwise substantial percentage of undecided voters decreases sharply in weeks leading up to an election and gradually increases afterwards. This paper models the dynamics of this asymmetric electoral cycle using artificial neural networks, with the purpose of estimating when the undecided voters start making up their minds. We find that they begin to decide which party to vote for nine weeks before a first order national parliamentary election and one to four weeks before a second order election, depending on the type of election (European Parliament, Provincial States, City-councils). The effect of political campaigns and the implications for political analysis are discussed.
\end{abstract}

Keywords: Opinion polls, Elections, Neural network models

\footnotetext{
${ }^{*}$ Correspondence to Dick van Dijk, Tinbergen Institute, P.O. Box 1738, NL-3000 DR Rotterdam, The Netherlands, e-mail: djvandijk@few.eur.nl. GAUSS programs to estimate parameters in artificial neural networks will soon be available at http://www.eur.nl/few/ei/faculty/franses.
} 


\section{Introduction}

For most people voting is not instantaneous. They typically do not have to wait until election day to know which political party they tend to favor. The identification of these people with one of the major parties is the long-term influence on the vote which, under 'normal' circumstances, determines in large part the election outcome. However, next to these early-deciders or precommitted partisans there often are many undecided voters, even late in some election campaigns, and last-minute deciders. Dutch opinion polls suggest that the size of this group of undecided voters is quite substantial in the Netherlands. During periods when no elections are ahead up to $30 \%$ of the eligible adult electorate fails to mention a party when asked which party they would vote for if elections were held that day. This percentage declines precipitously to approximately $15 \%$ in weeks leading up to an election. Hence election outcomes also are, at least in part, the result of relatively sudden changes in the undecided voters' feelings about candidates and political parties in the final few weeks (or days or even hours) of an election campaign. As we will see, the recurring changes in the percentage of undecided voters appear in a cyclical fashion, driven by national parliamentary elections. The quantitative study of these electoral cycles is a relatively new field of investigation in political research (Bürklin 1987). Most of the attention from political scientists has been directed towards noncyclical phenomena and many traditional theories of political participation would interpret the cycles as a deviation from equilibrium or the 'normal' circumstances. This paper is a straightforward test of the theory of short electoral cycles formulated by several authors, recently by Stray and Silver (1983), Reif (1984), and Van der Eijk (1987) ${ }^{1}$. It uses a time series of survey-based vote intentions in the Netherlands and attempts to pinpoint the timing of vote decisions, that is, it considers the issue of how long before an election undecided voters make up their minds for which party to vote.

A variety of factors can be proposed to explain the process that moves the undecided voters through the electoral cycle. One is the suggestive covariation between the phases of the cycle and political party campaigning. During election campaigns political parties attempt to mobilize voters by modern campaign technologies and by heavy use of mass media. Campaign resources are poured into political advertising and media image making, and political candidates and their campaign staff temporarily shape the media

\footnotetext{
${ }^{1}$ The short-term electoral cycle examined here is obviously not to be confused with the cyclical pattern of election periods - realigning, stable alignment, and dealigning - across long stretches of time in American history (see, for example, Beck 1979). According to the periodicity principle of the partisan realigment theory, past American politics has followed regular cycles of stability and change in voter preference for the full sweep of electoral history (see Chubb, Flanigan, and Zingale 1980). Our data more closely resemble the cyclical pattern in by-election results as described by Stray and Silver $(1983,49)$ : "the support for the government declining after a general election, being at its lowest in mid-term, and then increasing as the next general election approaches" (See also Reif 1985, Van der Eijk 1987).
} 
agenda. This would be particularly true for Dutch national parliamentary elections, where extensive media coverage is provided ${ }^{2}$ and where mass media organizations often commission or report public opinion polls. The exposure of these polls and early projections may affect the intention to vote either in a bandwagon or an underdog direction (see Kavanagh 1981, Marsh 1984). It therefore seems plausible to assume that exposure to media coverage of elections, especially television coverage, would stimulate the intention to go and vote, although, as Morgan and Shanahan (1992) and Weaver (1996) note, heavy media emphasis on campaign strategy and maneuvering can also make some voters more cynical and less likely to vote. Television, Morgan and Shanahan (1992) argue, may narcotize and depolitize the viewing audience and thereby discourage participation.

Furthermore, mass media exposure to election campaigns are often hypothesized as influencing beliefs about the closeness of the election race, and some political observers tend to believe that more competitive election races increase vote intention and voter turnout (see Hofstetter 1973, Zimmer 1981, Cox and Munger 1989, and Aldrich 1993) ${ }^{3}$. The premise is that in a close race with no apparent front-runner the election outcome is less certain. This uncertainty generates more interest among the public over the outcome, which in turn becomes a stimulus leading more of the public to participate by voting than would be the case when the election is a landslide or perceived to be one-sided. A close election also provides rational reasons for people to vote. In a close race, more citizens may vote because they believe that each individual vote counts more and that their participation has a greater chance of affecting the outcome ${ }^{4}$. Another explanation of why closeness is related to turnout is that parties respond to closeness with greater effort at mobilization and get-out-the-vote campaigns (Cox and Munger 1989). In close-fought contests, an effective campaign can make the difference between victory and defeat.

A somewhat related explanation is that political campaigns intensify voters' feelings about politics which drives up their vote intention. In weeks leading up to an election political competition and intraparty conflict typically increase. Where current political controversies are deeply felt by large numbers of people, vote intentions should rise above preceding levels. Hence, pre-election periods are times in which party differences as per-

\footnotetext{
${ }^{2}$ In the Netherlands there are no political campaign commercials on television during general elections. Instead, the parties are given free air time to present their program to the electorate in a series of political broadcasts.

${ }^{3}$ It should be noted that electoral studies have typically confirmed the closeness-turnout link hypothesis but most microlevel studies have denied any link (see Nownes 1992). Hence it may be that the hypothesis suffers an aggregation bias (Matsusaka 1993).

${ }^{4}$ Obviously even in close-fought mass elections the instrumental value of voting is trivial because the probability of a single vote being pivotal is negligible - the 'paradox of not voting' (Ferejohn and Fiorina 1974). This is not to suggest that self-interest maximizing individuals will not participate in national elections because there is an infinitesimal probability that they could end up in a position to cast the decisive vote. For many the costs of voting are small and there may be (albeit low) benefits involved in not abstaining (see Aldrich 1993).
} 
ceived by the electorate appear to be sharpest and, thus, the best guide to make a decision.

There are therefore compelling reasons for giving the correspondence between political campaigning and the electoral cycle a causal interpretation. The mobilization efforts of parties during election campaigns do not necessarily result in long-term allegiances however. Many people vote, if at all, for the candidate, not the party, and having done so, abdicate partisan preferences. Moreover, the recurring increases in the number of undecided voters during post-election periods may be a response to the perceived gap between campaign promises and incumbent government performance. Unrealistically high initial expectations about what parties or the government will accomplish give way to disappointment at some time after the election (Stimson 1976, Sigelman and Knight 1985). Moreover, while the intention to vote for the parties who have won the election typically increases shortly after the election itself, presenting a 'halo' effect or a 'post electoral euphoria' that may even drive their popularity above the value expressed at the election result, voters for losing parties may temporarily be depressed and demobilized (Reif 1984, 1985). This may result in a loss of interest in politics, resignation and, in subsequent elections, nonvoting. Of course, this two-way switching of mobilization of winners and withdrawal by losers may cancel at the aggregate level of vote intention.

Although these explanations for the cyclical dynamics of vote intention pertain to all general elections, they are particularly relevant to what Reif and Schmitt (1980) call first order elections, i.e., those which allocate the most powerful and important political offices in a country. In the Netherlands, as in all parliamentary systems, these are the elections for the National Parliament. They constitute the most competitive contest because there is much at stake. Elections which are held in between the national parliamentary elections are the less-competitive second order elections. In the Netherlands these are the elections for the European Parliament, Provincial States, and City-councils. In these less-at-stake elections abstaining is generally perceived to have less serious consequences.

This paper examines the influence of first and second order elections on the percentage of undecided voters. The outline of this paper is as follows. Section 2 discusses the data and specifies our research questions. The data show complicated dynamic patterns which hint towards potential nonlinear structure. We consider the use of artificial neural networks [ANNs], which is also motivated by the specific nature of our research questions. Section 3 briefly outlines some key features of ANNs. In contrast to much empirical research in this area, we do not treat this model as a 'black box' but, on the contrary, we explicitly use it components for inference. Section 4 presents our empirical results for the weekly series of undecided voters and Section 5 provides interpretations of our findings and implications for political analysis. 


\section{The data and the research questions}

The data we use are taken from the NIPO Inc.'s Omnibus survey, a weekly survey based on personal interviews of a random cross-section sample of the Dutch population of age 18 and over. The number of respondents to the surveys equals just over 1,000 on average. A detailed description of the NIPO surveys is given in Eisinga and Felling (1992). The data we use are the responses to the question, asked in the same form in every survey, "Which party would you vote for if elections were held today?" taken over weekly intervals from the first week of 1978 to the last week of 1995, giving 921 observations in total. The measure we employ is the number of 'undecided voters', that is, the percentage not supporting a particular party as a proportion of the total number of responses to the vote intention question. Of the $(18 \times 52=) 936$ potential surveys the following ones are missing (last two digits of year followed by week number): 78.52, 79.01, 79.40, 79.52, 80.01, 81.01, 82.52, $83.08,83.31,84.52,85.52,87.01,89.52,90.52$, and 92.01. The series is graphed in Figure 1. Circles, cubes, triangles, and diamonds indicate elections for National and European Parliament, Provincial States, and City-councils, respectively. The exact election dates from 1974 to 1995 are listed in Table 1.

- insert Figure 1 -

\section{- insert Table 1 -}

As indicated, the most striking feature of this time series is its typical cyclical pattern. This cycle is closely connected to the dates of the first order national parliamentary elections: few weeks after each such election, the percentage of undecided voters starts displaying an upward movement, which gradually levels off and changes into a downward movement in weeks leading up to the next election. We define these periods of upward and downward movement as post-election and pre-election regimes, respectively, and one post- and one pre-election regime together constitute an election cycle. This election cycle is seen to be rather asymmetric, as the post-election regime in general lasts much longer than the pre-election regime, notable exceptions being the cycles following the regularly scheduled election held in May 1981 and the early election of September 1982 caused by the untimely fall of the coalition government. As such asymmetry in general cannot be modeled using linear time series models ${ }^{5}$, it seems likely that some nonlinear structure is present in the data.

\footnotetext{
${ }^{5}$ This conjecture is based on the election cycle's similarity with the business cycle, where upward and downward movements correspond to expansions and recessions, respectively. Asymmetry in the business cycle has been documented extensively, see Ramsey and Rothman (1996) and Sichel $(1993,1994)$ for recent discussions, and is generally modeled using nonlinear models.
} 
Second order elections (i.e., those for European Parliament, Provincial States, and City-councils) seem to hamper the general cyclical pattern as they cause a temporary decline, which is restored fairly quickly after the particular election has been held (and is not followed immediately by another election). If we disregard the election cycle, there seems to be a slight upward trend in the percentage of undecided voters, at least until 1994. This trend towards less party voting parallels the well-known and much-maligned decline in electoral turnout rates in many Western industrial democracies in the past few decades (e.g., Shaffer 1981, Abramson and Aldrich 1982, Chen 1992, Flickinger and Studlar 1992, Armingeon 1994, Fenster 1994, and Nardulli, Dalager, and Greco 1996). It is fairly well accepted, although not always rigorously documented, that this decline is generated, among others, by long-term factors such as a decline in the saliency of politics for most citizens, a decline in the attachment of voters to parties and an increase in political alienation, especially a rise in feelings of powerlessness or lack of efficacy, and apathy (see Shaffer 1981, Abramson and Aldrich 1982, Chen 1992, Aldrich 1993, Armingeon 1994, and Southwell 1995). These changes may obviously be the result of the turnover of electoral generations and of other structural changes such as a shifting age distribution. Moreover, as can be seen in both Figure 1 and Table 1, the election calendar has frequently called Dutch voters to the polls. The increased number of elections may have gradually devaluated the importance of any single election and may have induced voter fatigue. From August 1992 until approximately June 1993, there is a slight decrease which cannot be ascribed to a de facto election. This anomaly might be attributed to the fact that during this period early elections were foreseen. At the time, the Dutch coalition cabinet faced great internal disagreement over several policy reviews and many people anticipated the demise of the coalition government and thus an early election. The major issue in the media, for example, was not whether there would be an early election but when. The multiparty coalition ultimately experienced no early termination however. It averted the crisis and remained in office for the complete term until the next regular scheduled election of May 1994.

In this paper, we formally investigate the influence of first and second order elections on the percentage of undecided voters. More specifically, we address the following three questions.

1. How long before an election does the downward movement in the percentage of undecided voters begin?

2. What is the size of the downward movement, i.e., how large is the decline in percentage points? 
3. Do first and second order elections have similar effects on the decline in the percentage of undecided voters with respect to timing and magnitude?

We address these questions in the context of artificial neural network [ANN] models. As explanatory variables in our models we use lagged values of the percentage of undecided voters, denoted $y_{t}$, as well as the number of weeks until and after the various elections held in the Netherlands. We denote the latter as $t_{u, j}$ and $t_{a, j}$, respectively. The subscript $j$ is used to identify the type of election, $j=N P, E P, P S$, or $C C$ corresponding to elections for National and European Parliaments, Provincial States, and City-councils, respectively. The variables $t_{u, j}$ and $t_{a, j}$ have been rescaled by dividing them by the maximum number of weeks between two elections of the same type (which equals 260, for elections for European Parliament are held once in every five years) and subtracting this from 1 . This transformation guarantees that the 'until' and 'after' variables are equal to one at the time of elections of the corresponding type ${ }^{6}$, which facilitates interpretation of the NN-estimation results, as will be discussed below. In the next section, we provide some background information about ANN models.

\section{Artificial Neural Networks}

Artificial neural network models, or simply artificial neural networks [ANNs], have been adopted from cognitive science, and are inspired by the way information is thought to be processed in the human brain. Although ANNs are 'merely' nonlinear regression models, perhaps because of their origin there is some mystique associated with them, which is accentuated by the rather exotic names given to the various ingredients of ANNs, such as input and output units, connection strengths, neurons, hidden layers, and activation functions. We refer the interested reader to Ripley $(1993,1994,1996)$ for general introductions to ANN models. Here we restrict attention to one particular form of these models, called the single layer feedforward neural network model, which takes the form,

$$
y_{t}=\beta_{0}+\sum_{j=1}^{q} \beta_{j} F\left(\gamma_{j}^{\prime} z_{t}\right)+\varepsilon_{t},
$$

where $y_{t}, t=1, \ldots, T$ is the output or dependent variable, $z_{t}$ is a vector of input or explanatory variables, consisting of lagged endogenous and exogenous variables, i.e., in our case $z_{t}=\left(1, \tilde{z}_{t}\right)^{\prime}, \tilde{z}_{t}=\left(y_{t-1}, \ldots, y_{t-p}, t_{u, N P}, \ldots, t_{a, C C}\right)^{\prime}$. The activation functions $F(\cdot)$ in the $q$ so-called hidden units, $\beta_{j} F(\cdot)$, are taken to be logistic functions, i.e., $F(w)=$ $1 /(1+\exp (-w))$. Finally, the $\varepsilon_{t}$ is assumed to be a white noise process.

\footnotetext{
${ }^{6}$ In order to adequately capture the fact that the trough of the election cycle is reached after the election has been held, $t_{u, j}$ is set equal to 1 in the week immediately following an election of type $j$ as well.
} 
The ANN model with one hidden layer as given in (1) is the most popular form in applications to economic time series, see, e.g., Kuan and White (1994), Kuan and Liu (1995), and Swanson and White (1995), among others. It is seen that such an ANN really is nothing more than a regression model with a time-varying constant, where at each point in time the value of the intercept is determined by the values taken by the hidden units. However, if the number of hidden units, $q$, is taken sufficiently large, the single layer feedforward ANN (1) provides a very flexible modeling tool, which can accomodate a wide variety of dynamic patterns in the variable of interest, $y_{t}$.

In much empirical research, ANNs are treated as a 'black box', with the researcher having little knowledge, let alone control, of what is going on in the model or why particular results are obtained. In contrast, we explicitly employ the structure of the ANN to obtain interpretable results and draw empirical inference regarding the impact of the various types of elections on the percentage of undecided voters. For that purpose, we impose a particular structure on the so-called connection weights $\gamma_{j}$. First of all, we include four hidden units into the model in which the $\gamma_{j}$ 's are restricted in such a way that each of these units is governed only by a single 'until' variable, that is, $\gamma_{j}$ is such that the argument of the activation function in the $j$-th hidden unit, $\gamma_{j}^{\prime} z_{t}$, can be written as $\gamma_{j}^{\prime} z_{t}=\delta_{u, j}\left(t_{u, j}-\tau_{u, j}\right)$, where $j=N P, E P, P S, C C$. In the sequel, we will use the shorthand notation $F_{u, j}, j=N P, E P, P S, C C$, to denote the resulting activation functions. We impose the identifying restriction $\delta_{u, j}>0$, such that the function $F_{u, j}$ changes from zero to one as $t_{u, j}$ becomes larger. Because of the transformation which is applied to the time until elections of type $j$ (see Section 2), the $j$-th hidden unit becomes active whenever elections of type $j$ approach (only if these elections have any impact on the percentage of undecided voters of course). The parameter $\tau_{u, j}$ can be tentatively interpreted as the time when the $j$-th unit becomes active, as $F_{u, j}=.5$ when $t_{u, j}=\tau_{u, j}{ }^{7}$ The other parameter in $F_{u, j}, \delta_{u, j}$, indicates whether the transition from inactive to active is gradual $\left(\delta_{u, j}\right.$ small $)$ or fast $\left(\delta_{u, j}\right.$ large).

Concerning the time after elections, recall that the election cycle appears to be driven by the time relative to elections for National Parliament. As will be evident from Figure 1, the impact of the second order elections for European Parliament, Provincial States, and City-councils is relatively small when compared to the effects of the first order elections for National Parliament. For this reason, we only allow the time after elections for National Parliament, $t_{a, N P}$, to enter the model. In a similar vein as discussed above, we include this variable by adding another hidden unit which is controlled by $t_{a, N P}$ only, i.e., with

\footnotetext{
${ }^{7}$ Note that this interpretation of $\tau_{u, j}$ as the starting point of the election effect is valid only if $\delta_{u, j}$ is large, such that $F_{u, j}$ changes almost instantaneously from zero to one as $t_{u, j}$ becomes larger than $\tau_{u, j}$. If $\delta_{u, j}$ is small, the $j$-th hidden unit becomes active much earlier, as $F_{u, j}$ is already nonzero long before $t_{u, j}$ becomes equal to $\tau_{u, j}$.
} 
$\gamma_{j}^{\prime} z_{t}=\delta_{a, N P}\left(t_{a, N P}-\tau_{a, N P}\right), \delta_{a, N P}>0$. Finally, to accomodate temporal dependence in our time series, we add four lagged values of the endogenous variable as well. Hence, our basic model is given by,

$$
y_{t}=\phi_{0}+\sum_{i=1}^{p} \phi_{i} y_{t-i}+\sum_{j=N P}^{C C} \beta_{u, j} F\left(\delta_{u, j}\left(t_{u, j}-\tau_{u, j}\right)\right)+\beta_{a, N P} F\left(\delta_{a, N P}\left(t_{a, N P}-\tau_{a, N P}\right)\right)+\varepsilon_{t} .
$$

The ANN (2) implicitly assumes that only the level of the series changes over time. However, the dependence between consecutive observations might change as well. Comparing autocorrelations for subsamples consisting of observations shortly before election dates and of other observations (not reported here) reveals that this indeed seems to be the case. It is straightforward to extend the ANN (2) to allow for varying autoregressive parameters as well, by augmenting the intercepts $\beta_{u, j}$ in the hidden units with linear combinations $\sum_{i=1}^{p} \theta_{i, j} y_{t-i}$, for $j=N P, E P, P S, C C$. With four hidden units, the number of parameters to be estimated would increase substantially. Moreover, the parameters $\theta_{i, j}$ are estimated using only a small number of observations, as the hidden units are expected to become active only in the final few weeks before elections, which are held only four or five times during the sample period. Therefore, we will assume that the coefficients corresponding to lagged $y_{t}$ 's are affected in the same way by each type of election, and that the effect of two elections which are close by is the same as that of isolated elections. These restrictions can conveniently be incorporated by extending model (2) as follows,

$$
\begin{aligned}
y_{t}= & \phi_{0}+\sum_{i=1}^{p} \phi_{i} y_{t-i}+\sum_{i=1}^{4} \theta_{i} y_{t-i}\left(1-\Pi_{j=N P}^{C C}\left[1-F\left(\delta_{u, j}\left(t_{u, j}-\tau_{u, j}\right)\right)\right]\right)+ \\
& \sum_{j=N P}^{C C} \beta_{u, j} F\left(\delta_{u, j}\left(t_{u, j}-\tau_{u, j}\right)\right)+\beta_{a, N P} F\left(\delta_{a, N P}\left(t_{a, N P}-\tau_{a, N P}\right)\right)+\varepsilon_{t} .
\end{aligned}
$$

To understand that the multiplicative term $\left(1-\Pi_{j=N P}^{C C}\left[1-F_{u, j}\right]\right)$ in (3) serves our purpose, note that it equals zero in times when no elections are close by as all $F_{u, j}$ are then equal to zero. When an election of type $j$ approaches, $F_{u, j}$ changes from zero to one, $1-F_{u, j}$ does the opposite, $\Pi_{j=N P}^{C C}\left[1-F_{u, j}\right]$ also switches from one to zero, such that the complete term changes from zero to one. Also note that if two elections are that close that their individual hidden units become active simultaneously the multiplicative term still equals one. In order to distinguish model (3) from model (2), we will call the former a multiplicative neural network [MNN]. In the next section we discuss and interpret estimates of the ANN and MNN models (2) and (3) for our weekly time series of percentages of undecided voters.

\section{Results}

In this section we discuss estimates of the models (2) and (3) for the weekly observed percentage of undecided voters in the Netherlands. We also estimate models with certain 
restrictions imposed to investigate similarities between different types of elections. To choose between the different models, we use the Akaike and Schwarz Information Criteria [AIC and SIC, respectively]. These criteria are computed as $\mathrm{AIC}=\ln \sigma_{\varepsilon}^{2}+2 k / T$ and $\mathrm{SIC}=\ln \sigma_{\varepsilon}^{2}+k \ln (T) / T$, where $\sigma_{\varepsilon}^{2}$ is the residual variance and $k$ is the number of estimated parameters in the model. Granger et al. (1995) advocate the use of such criteria for model selection because in this approach no particular model is favored a priori. An obvious drawback of this procedure is that all competing models have to be estimated, which can become rather time-consuming if the number of relevant alternative models is large. Throughout we include four lagged values of the dependent variable in the model, i.e., we set $p$ in (2) and (3) equal to 4 . A dummy variable $D_{t}$, which equals 1 in week 81.43 and zero otherwise is also included. The outlier in this single week, which is clearly visible in Figure 1 , is caused by a failure of the survey organization's error-control procedure resulting in a one-of-a-kind overrepresentation of undecided voters composed largely of misclassified early deciders.

In general, estimation of ANN models is hampered by the fact that the model is not identified, and that the hidden units tend to be highly correlated. For that reason, quite complicated and ambiguous estimation procedures have to be used to estimate ANNs. In contrast, because of the structure we have imposed on the hidden units, our ANN models in (2) and (3) are identified. Although we still expect the hidden units to be correlated to some extent as elections of different types are often held quite close to each other, we decide to estimate our models using nonlinear least squares.

\subsection{Constant autoregressive parameters}

First of all, we consider the ANN model (2) with constant autoregressive parameters. The model is estimated as follows,

$$
\begin{aligned}
& y_{t}=4.262+9.603 D_{t}+0.458 y_{t-1}+0.178 y_{t-2}+0.111 y_{t-3}+0.113 y_{t-4}
\end{aligned}
$$

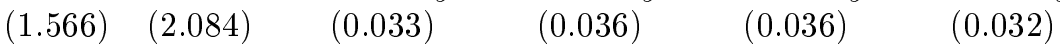

$$
\begin{aligned}
& -2.076 F_{u, N P}-1.281 F_{u, E P}-3.023 F_{u, P S}-1.573 F_{u, C C}-2.370 F_{a, N P}+\varepsilon_{t},{ }^{(4)} \\
& (0.376)
\end{aligned}
$$

where standard errors are given in parentheses below the parameter estimates.

The impact of elections can be decomposed in 'timing' and 'magnitude', cf. questions 1 and 2, respectively, as posed in Section 2. Franses and Draisma (1997) suggest to examine plots of the values taken by the hidden units over time to get some idea of the contribution of the various nonlinear components to the overall model output. Here we use this graphical device to assess the timing aspect of the influence of the different types of elections. The activation functions $F_{u, j}$ (multiplied by 10, in order to increase visibility) in (4) have been graphed in Figure 2 for each type of election separately. 


\section{- insert Figure 2 -}

It is seen that the hidden unit corresponding to a particular type of election becomes active only a short while before elections are held. The estimates of the constants $\tau_{u, j}$ give an indication of the length of this period. The estimates (standard errors in parentheses) are given as $\tau_{u, N P}=0.966(0.032), \tau_{u, E P}=0.981(0.019), \tau_{u, P S}=0.996(0.001)$, and $\tau_{u, C C}=0.983(0.013)$. Translated back into number of weeks prior to election these estimates become 9, 4, 1, and 4. That is, 9 weeks before elections for National Parliament are held does the number of undecided voters start decreasing, etc., see also Table 2. The unreported estimates of $\delta_{u, j}$ are very large, such that the value of the activation function $F_{u, j}$ switches almost instantaneously from 0 to 1 as the number of weeks until elections of type $j$ becomes equal to the number of weeks implied by the estimates of $\tau_{u, j}$.

\section{- insert Table 2 -}

The impact of elections in terms of the magnitude of the decrease in the percentage of undecided voters can be assessed by computing the difference between the expected value of $y_{t}$ in (4) and the expected value of $y_{t}$ if the activation functions would not become active. If elections of type $j$ are held at time $T$ and the corresponding hidden unit becomes active $s$ weeks before, the impact on the percentage of undecided voters in week $T-s+k, k=$ $0,1, \ldots, s$, denoted as $I_{j}\left(y_{T-s+k}\right), j=N P, \ldots, C C$, is given by

$$
I_{j}\left(y_{T-s+k}\right)=\sum_{i=1}^{p} \phi_{i} I_{j}\left(y_{T-s+k-i}\right)+\beta_{u, j} F_{u, j},
$$

where $I_{j}\left(y_{T-s+l}\right)=0$ if $l<0$. When computing the impact of elections for National Parliament we should take into account the effect of the hidden unit corresponding to the time after these elections, $F_{a, N P}$. As the output of this unit is rather small shortly before elections we neglect it for simplicity. Using the estimates in (4), the impact of the elections for National and European Parliaments, Provincial States and City-councils in the week the elections are being held, $I_{j}\left(y_{T}\right)$, are estimated to be $8.81,2.83,3.02$, and 3.59 percentage points in absolute value. Especially for the first order national parliamentary elections this seems to be a rather modest decrease, also because Figure 1 suggests that the decline at the time of these elections seems much larger. However, it should be observed that, except for 1981, other elections are held just before or just after the elections for national parliament. Hence, the total decline is an accumulation of impacts of different elections. This point is also illustrated in Figure 3. The middle panel of this Figure shows the values of the activation functions for all elections simultaneously. This graph reveals that, due to the proximity of different elections, the different hidden units are activated almost immediately following each other. In fact, sometimes more than one hidden unit 
is active. In the lower panel of Figure 3, the hidden unit corresponding to the time after elections for National Parliament is also shown. It is seen that the output of this unit changes very slowly. Among others, this suggests that it takes quite a long time before the percentage of undecided voters is back at its pre-election high level, which amounts to clear evidence of asymmetry in the data.

\section{- insert Figure 3 -}

Similarities between different types of elections can be examined by testing restrictions on the hidden units $F_{u, j}$ and/or the parameters $\beta_{u, j}$. We estimate several special cases of (2) and compare the values of the model selection criteria AIC and SIC. First of all, it is of interest to examine whether the elections have any impact at all. This question is adressed by estimating model (2) without the hidden units controlled by the time until the various elections. In Table 3, the values for the model selection criteria are given in the row $\beta_{u, N P}=\beta_{u, E P}=\beta_{u, P S}=\beta_{u, C C}=0$. A second question of interest is whether the timings of the election effects are significantly different from each other. For that purpose, model (2) is estimated with the restrictions $\tau_{u, N P}=\tau_{u, E P}=\tau_{u, P S}=\tau_{u, C C} \equiv \tau_{u}$

and $\delta_{u, N P}=\delta_{u, E P}=\delta_{u, P S}=\delta_{u, C C} \equiv \delta_{u}$ imposed. This renders an estimate of $\tau_{u}=$ 0.984 (and $\delta_{u}$ still very large) and AIC and SIC values as shown in Table 3 , in the row $F_{u, N P}=F_{u, E P}=F_{u, P S}=F_{u, C C} \equiv F_{u}$. Similarly, we test whether the second order elections for European Parliament, Provincial States, and City-councils have any impact $\left(\beta_{u, E P}=\beta_{u, P S}=\beta_{u, C C}=0\right)$, and if so, whether they differ from each other with respect to timing $\left(F_{u, E P}=F_{u, P S}=F_{u, C C} \equiv F_{u}\right)$.

\section{- insert Table 3 -}

The values of the information criteria for the various variants of the ANN in Table 3 indicate that the AIC favors the unrestricted model (4), in which all elections are allowed to have different effects. The model in which the timing of the effects of second-order elections are equal is a close competitor, and is preferred by the SIC. Hence we conclude that the hidden units contribute to explaining the movements in the percentage of undecided voters. According to AIC, first order and second order elections start to have an effect at different times before an election is held, while there appears to be considerable similarity between the different second order elections. According to SIC, second order elections might have no effect at all, or the importance of the first order elections might be questioned.

\subsection{Time-varying autoregressive parameters}

While the models discussed in the previous subsection appear to provide quite convincing and intuitive results for the impact of elections on the number of undecided voters, they are 
restrictive in the sense that the autoregressive parameters are assumed to be constant over time. The MNN model (3), which does not impose this restriction, is initially estimated as follows,

$$
\begin{aligned}
y_{t}= & 4.316+9.736 D_{t} \\
& (1.143) \quad(2.061) \\
& +0.402 y_{t-1}+0.237 y_{t-2}+0.115 y_{t-3}+0.100 y_{t-4}+ \\
& (0.035) \quad(0.038) \quad(0.038) \quad(0.034) \\
{[} & \left.0.467 y_{t-1}-0.493 y_{t-2}+0.094 y_{t-3}+0.021 y_{t-4}\right] \times\left[1-\Pi_{j=N P}^{C C}\left(1-F_{u, j}\right)\right] \\
& (0.098) \quad(0.119) \quad(0.105) \quad(0.096) \\
& -3.558 F_{u, N P}-2.934 F_{u, E P}-3.108 F_{u, P S}-2.902 F_{u, C C}-2.363 F_{a, N P}+\varepsilon_{t} . \quad(6) \\
& (1.137) \quad(1.272) \quad(1.473)
\end{aligned}
$$

Although some of the estimates of the autoregressive parameters are not significant, we decide not to simplify this model, but instead focus again on the output of the hidden units. The activation functions $F_{u, j}$ are examined to assess the impact of elections. Figure 4 shows the individual activation functions, again multiplied by 10 , while in Figure 5 they are graphed for all elections simultaneously. The output is seen to correspond quite closely with the results from model (2) (see also Table 2). The main difference occurs in the hidden unit corresponding to the elections for City-councils: the estimate of the constant $\tau_{u, C C}$ is now equal to $\tau_{u, C C}=0.989(0.076)$, which implies that activity of the hidden unit is restricted to 2 weeks prior to elections. Again, the impact of elections in terms of magnitude of decrease can be estimated by computing the difference in the expected value of $y_{t}$ due to the activity of the corresponding hidden unit. Note that the impact now is computed as,

$$
I_{j}\left(y_{T-s+k}\right)=\sum_{i=1}^{p} \phi_{i} I_{j}\left(y_{T-s+k-i}\right)+\left(\sum_{i=1}^{p} \theta_{i} I_{j}\left(y_{T-s+k-i}\right)+\beta_{u, j}\right) F_{u, j} .
$$

Using the estimates in (6), the impact of elections for National and European Parliaments, Provincial States, and City-councils in the week the elections are being held, $I_{j}\left(y_{T}\right)$, are estimated to be $18.92,8.18,3.11$, and 5.45 percentage points in absolute value. These estimates differ considerably from the impact estimates based on the ANN (4), and perhaps appear to be somewhat more reasonable.

The same restrictions with respect to existence and timing of the effect of elections as in the previous subsection have been examined by estimating different special cases of the MNN (3). The values of the model selection criteria are given in the two rightmost columns of Table 3. It appears that this time the AIC favors the model in which the timing of second order election effects are identical, while the SIC prefers the model in which no distinction is made between first and second order elections. 


\section{Conclusions and discussion}

While our results may not be surprising, they do represent, to the best of our knowledge, the first quantitative estimates of short-term cycles in self-reported vote intention. The ANNs models reported here demonstrate that first and second order Dutch elections have an unequal impact on the timing of vote decisions of undecided voters and on the change of the size of this group in the final few weeks before election. The estimates show that undecided Dutch voters begin to make up their minds nine weeks before a first order national parliamentary election and one (Provincial States) to four weeks (European Parliament and City-councils) before a second order election. Whereas first order national parliamentary elections drive up the proportion of voters considerably, second order elections expand this group by a few percentage points only.

At the outset of this paper, we reviewed several possible explanations for this cyclical pattern in vote intention. They all lead to the suspicion that the electoral cycles reflect the impact of party campaigning. They are so closely fit to the election dates that they leave little room for additional explanation. Why else should vote intention behave in this fashion and with such regularity? Hence while the analysis presented here does not directly speak to this question, the results suggest that the electoral cycles are the time-related effects of time-related campaigns.

Election campaigns have for a long time been thought to have limited effects on voters because partisan precommitment of early deciders would be sufficient to preclude campaign effects and because the remainder of the voters, who are presumed to lack interest in political news, would lack exposure to the campaign. Indeed, Chaffee and Choe (1980) and Whitney and Goldman (1985) show that precommitted voters or already-decided partisans are also those least likely to be swayed by campaign messages. These people have already decided on a candidate or party before the campaign gets underway and they attend media reports only to reinforce existing preferences. However, the authors also find that in the absence of a precampaign decision, those exposed to the heavy flow of information during the campaign decide primarily on the basis of this information (see also Caldeira, Clausen, and Patterson, 1990, Bowen 1994, and Finkel and Schrott 1995). It is the undecided, those who make their decision during the conduct of the campaign, who are most affected by the campaign message. Obviously, if parties are to win, they must both mobilize their existing support and reach out to those who have not yet decided. As the undecided voters are often the key to a winning election, they are a major target for electoral campaigns. In the Netherlands there is no legally recognized, official, or formal campaign period prior to the election. Dutch election law only requires that the nomination of candidates be established seven weeks before polling day. Election campaigns for the National Parliament generally 
include only the final three or four weeks before the election, but in the 'pre-campaign' period parties have already nominated their candidates and leader, and presented their election program to the electorate.

Huckfeld and Sprague (1992) show that active campaigns are more effective at getting the votes out than moribund campaigns. This explains why in first order national parliamentary elections undecided voters make up their minds earlier than in second order elections and why there are many first-order-election-only voters. The strategic efforts of political parties and their leaders and the features of a particular campaign environment affect the timing of participation and thus the aggregate rise and fall of participation within and across electoral cycles. In more-at-stake first order elections the amount and quality of campaigning and partisan efforts, television time given to parties, and media coverage are typically greater than in less-at-stake second order elections. The latter, particularly the Euro elections, generally have very little appeal for party activists. One could therefore also argue that campaign efforts are more important at second order elections than at first order elections. In the latter, there is generally much more attention given by the public (media as well as voters), because the entire political life of the country is focused on this event.

The results also suggest some implications for political analysis. Several election analysts have shown that the percentage of survey respondents who say that they will vote consistently outnumbers official turnout statistics. Similarly, respondents to post-election surveys claim retrospectively higher turnout voting than actually occurred (see Anderson and Silver 1986, Sigelman 1982, Hill and Hurley 1984, Swaddle and Heath 1989, Smeets 1995, and Marsh 1985). This study has made some progress on previous research by showing that the point in time a particular survey is conducted substantially affects the estimates of self-reported vote intention. Surveys administered in between elections may even underestimate actual turnout, sometimes quite dramatically so. In the same vein, comparative studies of survey-based turnout (longitudinal as well as cross-national) should pay close attention to the timing of the surveys used in the comparison ${ }^{8}$. Last but by no means least, this paper has shown that artificial neural network models [ANNs] do not necessarily have to be treated as a black box. They can explicitly be used for inference. Needless to say that this depends in part on the research problem at hand.

\footnotetext{
${ }^{8}$ Examples of cross-national comparative studies of voter turnout, either based on survey data or official statistics, are Powell (1986), Pettersen (1989), Flickinger and Studlar (1992), Armingeon (1994), Hirczy (1994), Jackman and Miller (1995), and Pacek and Radcliff (1995).
} 


\section{References}

Abramson, Paul R. and John H. Aldrich (1982) The Decline of Electoral Participation in America, American Political Science Review, 76, 502-521.

Aldrich, John H. (1993) Rational Choice and Turnout, American Journal of Political Science, 37, $246-278$.

Anderson, Barbara A. and Brian D. Silver (1986) Measurement and Mismeasurement of the Validity of the Self-reported Vote, American Journal of Political Science, 30, 771-785.

Armingeon, Klaus (1994) Gründe und Folgen Geringer Wahlbeteiligung, Kölner Zeitschrift für Soziologie und Sozialpsychologie, 46, 43-64.

Beck, Paul Allen (1979) The Electoral Cycle and Patterns of American Politics, British Journal of Political Science, 9, 129-156.

Bowen, Lawrence (1994) Time of Voting Decision and Use of Political Advertising: The Slade Gorton-Brock Adams Senatorial Campaign, Journalism Quarterly, 71, 665-675.

Bürklin, Wilhelm P. (1987) Why Study Political Cycles?, European Journal of Political Research, 15, 131-143.

Caldeira, Gregory A., Aage R. Clausen and Samuel C. Patterson (1990) Partisan Mobilization and Electoral Participation, Electoral Studies, 9, 191-204.

Chaffee, Steven H. and Sun Yuel Choe (1980) Time of Decision and Media Use During the Ford-Carter Campaign, Public Opinion Quarterly, 44, 53-69.

Chen, Kevin (1992) Political Alienation and Voting Turnout in the United States, 1960-1988, San Francisco: Mellen Research University Press.

Chubb, Jerome M., William H. Flanigan and Nancy H. Zingale (1980) Partisan Realigment: Voters, Parties, and Government in American History, Beverly Hills: Sage Library of Social Research.

Cox, Gary W. and Michael C. Munger (1989) Closeness, Expenditures, and Turnout in the 1982 U.S. House Elections, American Political Science Review, 83, 217-231.

Eisinga, Rob and Albert Felling, (1992) Confessional and Electoral Alignments in the Netherlands 1962-1992, Steinmetz Archive, Amsterdam.

Fenster, Mark J. (1994) The Impact of Allowing Day of Registration Voting on Turnout in the U.S. Elections from 1960 to 1992. A Research Note, American Politics Quarterly, 22, 74-87.

Ferejohn, John and Morris P. Fiorina (1974) The Paradox of Not Voting: A Decision Theoretic Analysis, American Political Science Review, 68, 525-536.

Finkel, Steven E. and Peter R. Schrott (1995) Campaign Effects on Voter Choice in the German Election of 1990, British Journal of Political Science, 25, 349-378.

Flickinger, Richard S. and Donley T. Studlar (1992) The Disappearing Voters? Exploring Declining Turnout in Western European Elections, West European Politics, 15, 1-16.

Franses, Philip Hans and Gerrit Draisma (1997) Recognizing Changing Seasonal Patterns Using Artificial Neural Networks, Journal of Econometrics, forthcoming.

Granger, Clive W.J., Maxwell L. King and Halbert White (1995) Comments on Testing Economic Theories and the Use of Model Selection Criteria, Journal of Econometrics, 67, 173-188.

Hill, Kim Quaile and Patricia A. Hurley (1984) Nonvoters in Voters' Clothing: The Impact of Voting Behavior Misreporting on Voting Behavior Research, Social Science Quarterly, 65, 199-206. 
Hirczy, Wolfgang (1994) The Impact of Mandatory Voting Laws on Turnout: A Quasi-experimental Approach, Electoral Studies, 13, 64-76.

Hofstetter, C.R. (1973) Inter-party Competition and Electoral Turnout, American Journal of Political Science, 17, 351-366.

Huckfeldt, Robert and John Sprague (1992) Political Parties and Electoral Mobilization: Political Structure, Social Structure, and the Party Canvass, American Political Science Review, 86, $70-86$.

Jackman, Robert W. and Ross A. Miller (1995) Voter Turnout in the Industrial Democracies During the 1980s, Comparative Political Studies, 27, 467-492.

Kavanagh, Dennis (1981) Public Opinion Polls, in David Butler, Howard R. Penniman and Austin Ranney (eds.), Democracy at the Polls. A Comparative Study of Competitive National Elections, pp. 196-215, Washington: American Enterprise Institute for Public Policy Research.

Kuan, Chung-Ming and Halbert White (1994) Artificial Neural Networks: An Econometric Perspective, Econometric Reviews, 13, 1-143 (with discussion).

Kuan, Chung-Ming and Tung Liu (1995) Forecasting Exchange Rates Using Feedforward and Recurrent Neural Networks, Journal of Applied Econometrics, 10, 347-364.

Marsh, Catherine (1984) Back on the Bandwagon: The Effect of Opinion Polls on Public Opinion, British Journal of Political Science, 15, 51-74.

Marsh, Catherine (1985) Predictions of Voting Behaviour from a Pre-election Survey, Political Studies, 33, 642-648.

Matsusaka, John G. (1993) Election Closeness and Voter Turnout: Evidence from California Ballot Propositions, Public Choice, 76, 313-334.

Morgan, Michael and James Shanahan (1992) Television Viewing and Voting 1972-1989, Electoral Studies, 11, 3-20.

Nardulli, Peter F., Jon K. Dalager and Donald E. Greco (1996) Voter Turnout in U.S. Presidential Elections: An Historical View and Some Speculation, PS: Political Science ES Politics, 26, 480-490.

Nownes, Anthony J. (1992) Primaries, General Elections, and Voter Turnout. A Multinominal Logit Model of the Decision to Vote, American Politics Quarterly, 20, 205-226.

Pacek, Alexander and Benjamin Radcliff (1995) Turnout and the Vote for Left-of-centre Parties: A Cross-national Analysis, British Journal of Political Science, 25, 137-143.

Pettersen, Per Arnt (1989) Comparing Non-voters in the USA and Norway: Permanence versus Transience, European Journal of Political Research, 17, 351-359.

Powell, G. Bingham Jr. (1986) American Voter Turnout in Comparative Perspective, American Political Science Review, 80, 17-43.

Ramsey, James B. and Philip Rothman (1996) Time Irreversibility and Business Cycle Asymmetry, Journal of Money, Credit and Banking, 28, 1-21.

Reif, Karlheinz (1984) National Electoral Cycles and European Elections 1979 and 1984, Electoral Studies, 3, 244-255.

Reif, Karlheinz (1985) Ten Second-order National Elections, in Karlheinz Reif, editor, Ten European Elections, pages 1-36. Aldershot, Gower.

Reif, Karlheinz and Hermann Schmitt (1980) Nine Second-order National Elections - A Conceptual Framework for the Analysis of European Election Results, European Journal of Political Research, 8, 3-44. 
Ripley, Brian D. (1993) Statistical Aspects of Neural Networks, in O.E. Barndorff-Nielsen, J.L. Jensen and W.S. Kendall (eds.), Chaos and Networks - Statistical and Probabilistic Aspects, pp. 40-123, Chapman and Hall, London.

Ripley, Brian D. (1994) Neural Networks and Related Methods for Classification (with discussion), Journal of the Royal Statistical Society B, 56, 409-456.

Ripley, Brian D. (1996) Pattern Recognition and Neural Networks, Cambridge University Press, Cambridge.

Shaffer, Stephen D. (1981) A Multivariate Explanation of Decreasing Turnout in Presidential Elections, 1960-1976, American Journal of Political Science, 25, 68-95.

Sichel, Daniel E. (1993) Business Cycles Asymmetry: A Deeper Look, Economic Inquiry, 31, $224-236$.

Sichel, Daniel E. (1994) Inventories and the Three Phases of the Business Cycle, Journal of Business and Economic Statistics, 12, 269-277.

Sigelman, Lee (1982) The Nonvoting Voter in Voting Research, American Journal of Political Science, 26, 47-56.

Sigelman, Lee and Kathleen Knight (1985) Expectation/Disillusion and Presidential Popularity: The Reagan Experience, Public Opinion Quarterly, 49, 209-213.

Smeets, Ingrid (1995) Facing Another Gap: An Exploration of the Discrepancies Between Voting Turnout in Survey Research and Official Statistics, Acta Politica, 30, 307-334.

Southwell, Priscilla (1995) Alienation and Nonvoting in the 1992 Presidential Elections, Journal of Political and Military Sociology, 23, 99-117.

Stimson, James A. (1976) Public Support for American Presidents: A Cyclical Model, Public Opinion Quarterly, 40, 1-21.

Stray, Stephanie and Mick Silver (1983) Government Popularity, By-elections and Cycles, Parliamentary Affairs, 36, 49-55.

Swaddle, Kevin and Anthony Heath (1989) Official and Reported Turnout in the British General Election of 1987, British Journal of Political Science, 19, 537-570.

Swanson, Norman R. and Halbert White (1995) A Model Selection Approach to Assessing the Information in the Term Structure Using Linear Models and Artificial Neural Networks, Journal of Business and Economic Statistics, 13, 265-275.

Van der Eijk, Cees (1987) Testing Theories of Electoral Cycles. The Case of the Netherlands, European Journal of Political Research, 15, 253-270.

Weaver, David H. (1996) What Voters Learn from Media, Annals of the American Academy of Political and Social Science, 546, 34-47.

Whitney, D. Charles and Steven B. Goldman (1985) Media Use and Time of Vote Decision. A Study of the 1980 Presidential Election, Communication Research, 12, 511-529.

Zimmer, Troy A. (1981) Media Exposure to Campaigns. Public Anticipation and Involvement in Elections, Communication Research, 8, 189-204. 
Table 1: Election dates in the Netherlands, $1974-1995^{1}$

\begin{tabular}{cccc}
\hline \hline \multicolumn{4}{c}{ Type of Election } \\
\hline NP & EP & PS & CC \\
\hline $05-25-77$ & & $03-27-74$ & $05-29-74$ \\
$05-26-81$ & & $03-29-78$ & $05-31-78$ \\
$09-08-82$ & $06-07-79$ & $03-24-82$ & $02-06-82$ \\
$05-21-86$ & $06-14-84$ & $03-18-87$ & $03-19-86$ \\
$09-06-89$ & $06-15-89$ & $03-06-91$ & $03-21-90$ \\
$05-03-94$ & $06-09-94$ & $03-08-95$ & $03-02-94$ \\
\hline
\end{tabular}

${ }^{1}$ Election dates (MM-DD-YY) in the Netherlands in the period 1974-1995. NP = National Parliament, $\mathrm{EP}=$ European Parliament, PS = Provincial States, $\mathrm{CC}=$ City-council.

Table 2: Timing of vote decision ${ }^{1}$

\begin{tabular}{cccccc}
\hline \hline & \multicolumn{2}{c}{ ANN } & & \multicolumn{2}{c}{ MNN } \\
\cline { 2 - 3 } \cline { 5 - 6 } Type of Election & $\tau_{u, j}$ & No. of weeks & & $\tau_{u, j}$ & No. of weeks \\
\hline NP & 0.966 & 9 & 0.963 & 9 \\
EP & 0.981 & 4 & 0.981 & 4 \\
PS & 0.996 & 1 & 0.996 & 1 \\
CC & 0.983 & 4 & & 0.989 & 2 \\
\hline
\end{tabular}

${ }^{1}$ Estimates of the constants in the activation functions in the ANN model (4) and the MNN model (6). NP = National Parliament, EP = European Parliament, PS $=$ Provincial States, $\mathrm{CC}=$ City-council.

Table 3: Selection criteria for model variants ${ }^{1}$

\begin{tabular}{lccccc}
\hline \hline \multirow{2}{*}{ Restriction } & \multicolumn{2}{c}{ ANN } & & \multicolumn{2}{c}{ MNN } \\
\cline { 2 - 3 } \cline { 5 - 6 } & AIC & SIC & & AIC & SIC \\
\hline$\beta_{u, N P}=\beta_{u, E P}=\beta_{u, P S}=\beta_{u, C C}=0$ & 1.543 & 1.590 & & 1.543 & 1.590 \\
$F_{u, N P}=F_{u, E P}=F_{u, P S}=F_{u, C C}$ & 1.504 & 1.567 & & 1.464 & 1.548 \\
$\beta_{u, E P}=\beta_{u, P S}=\beta_{u, C C}=0$ & 1.505 & 1.568 & & 1.495 & 1.580 \\
$F_{u, E P}=F_{u, P S}=F_{u, C C}$ & 1.487 & 1.566 & & 1.461 & 1.561 \\
\hline
\end{tabular}

${ }^{1}$ Model selection criteria for variants of ANN (4) and MNN (6). AIC = Akaike Information Criterion, SIC = Schwarz Information Criterion. NP = National Parliament, EP = European Parliament, PS = Provincial States, CC = City-council. The model with minimum values for AIC and SIC is preferred. 
Figure 1: Undecided voters in the Netherlands, 1978-1995

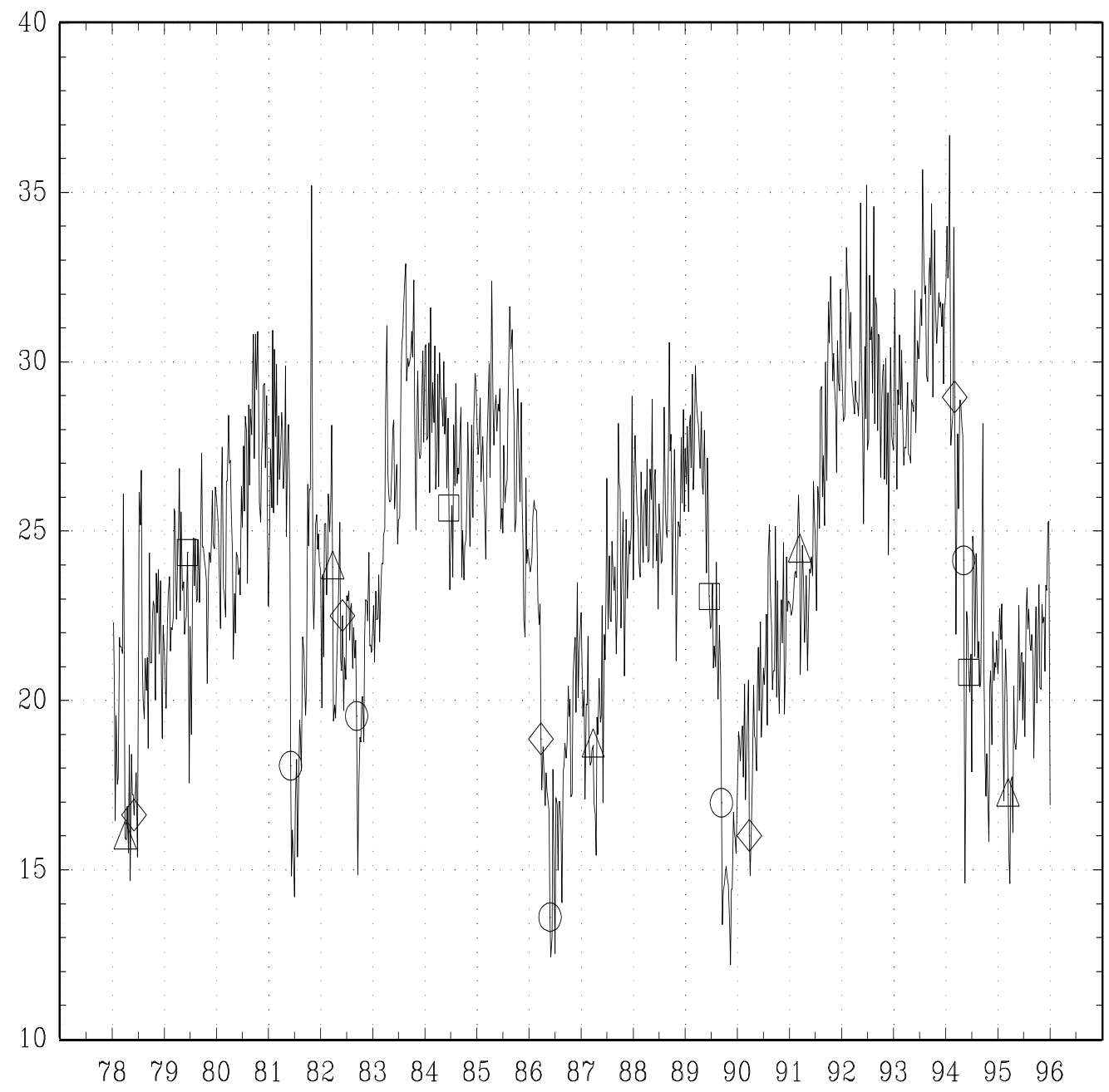

Note: Percentage of respondents who failed to mention a party to the question "Which party would you vote for if elections were held today?" Circles, cubes, triangles, and diamonds indicate elections for National and European Parliaments, Provincial States, and City-councils, respectively. 
Figure 2: Output of activation functions
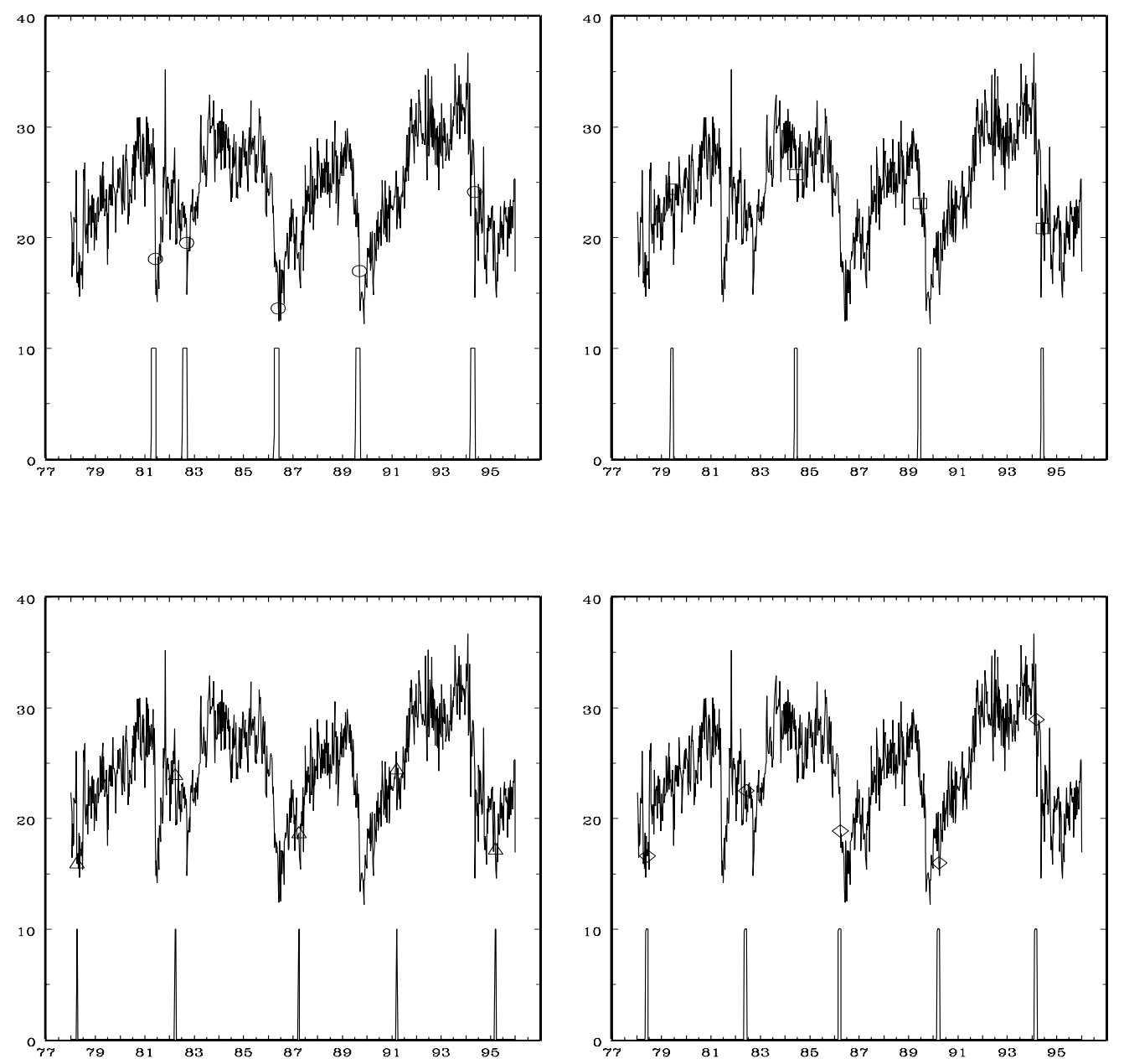

Note: Values taken by activation functions corresponding to National Parliament (upper left), European Parliament (upper right), Provincial States (lower left), and City-councils (lower right) in ANN (4). 
Figure 3: Output of activation functions
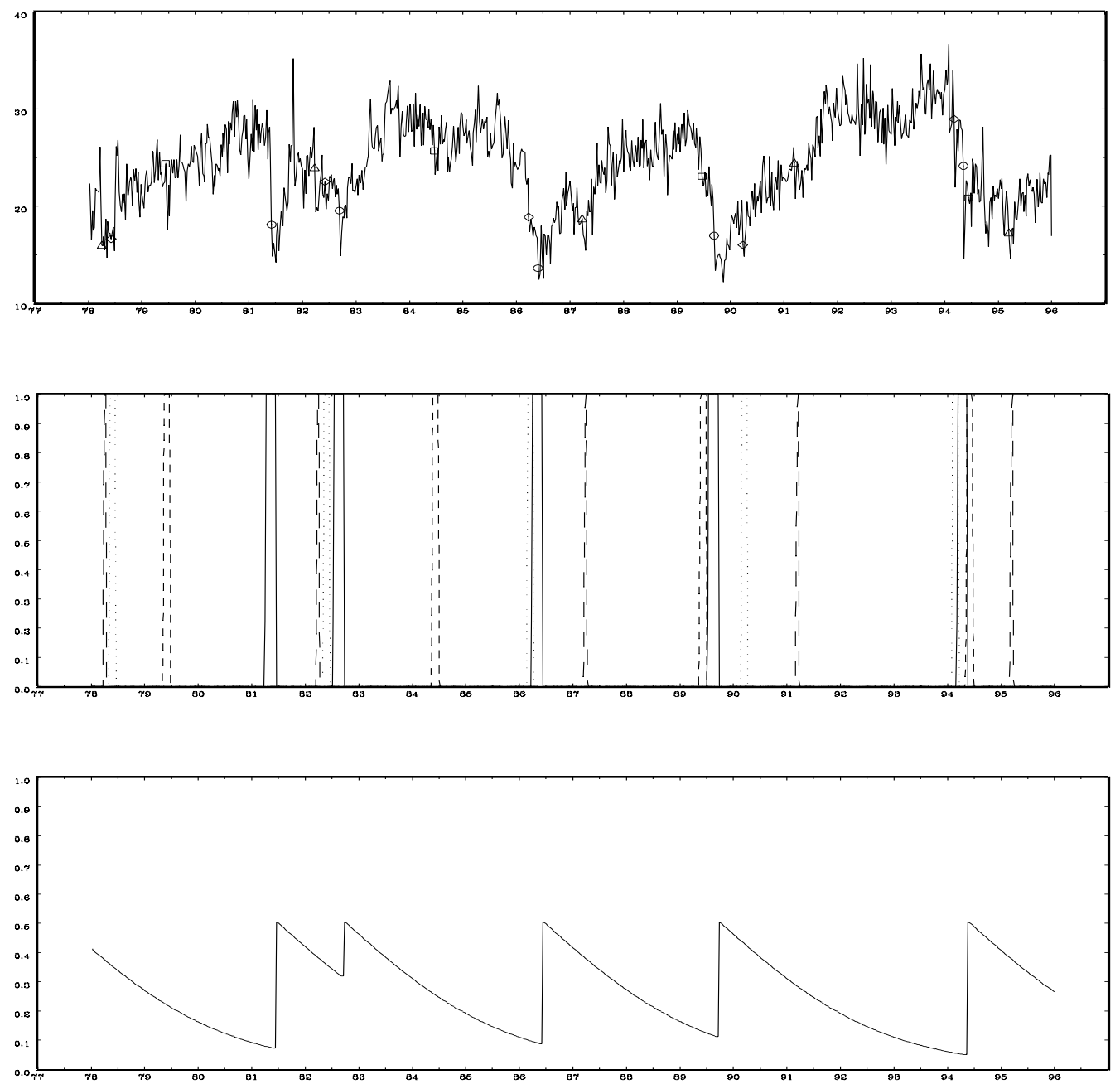

Note: The middle panel shows the values taken by the activation functions $F_{u, j}$ in ANN (4). Solid, short dashed, long dashed, and dotted lines indicate hidden units corresponding to time until next elections for National and European Parliaments, Provincial States, and City-councils, respectively. The lower panel shows the values taken by the activation function $F_{a, N P}$, corresponding to the time after elections for National Parliament. 
Figure 4: Output of activation functions
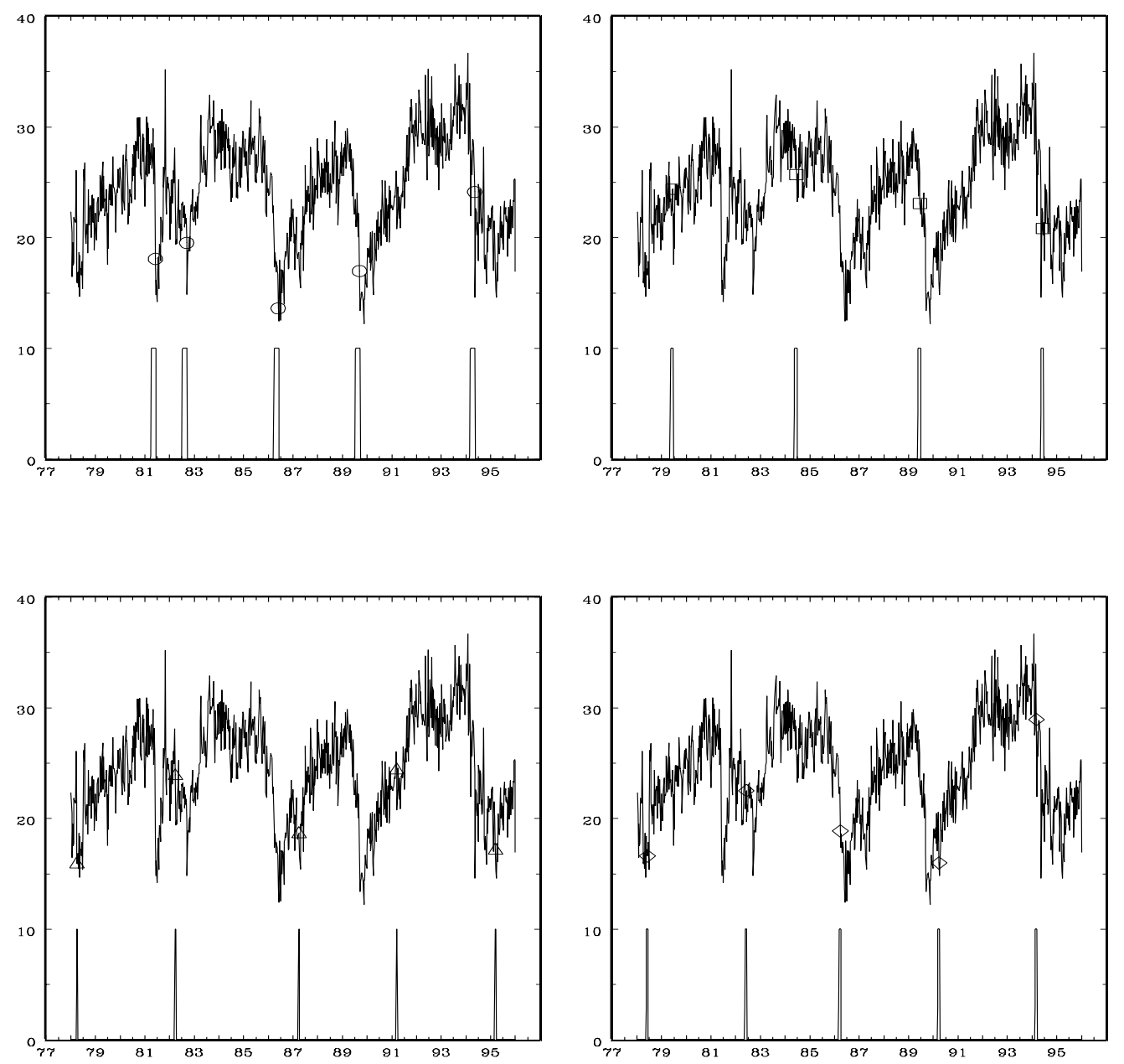

Note: Values taken by activation functions corresponding to National Parliament (upper left), European Parliament (upper right), Provincial States (lower left), and City-councils (lower right) in MNN (6). 
Figure 5: Activation functions
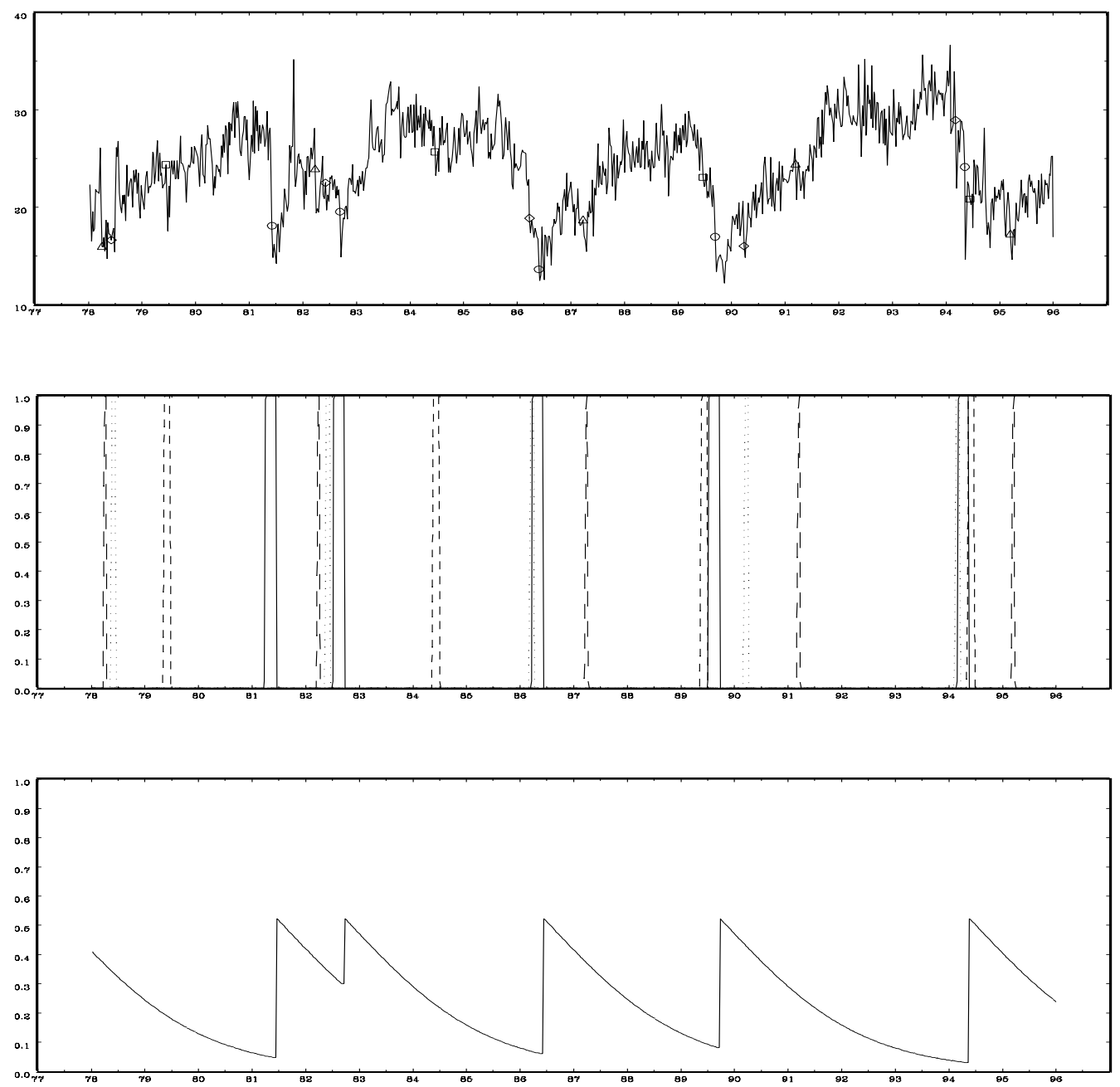

Note: The middle panel shows the values taken by the activation functions $F_{j}$ in MNN (6). Solid, short dashed, long dashed, and dotted lines indicate hidden units corresponding to time until next elections for National and European Parliaments, Provincial States, and City-councils, respectively. The lower panel shows the values taken by the activation function $F_{a, N P}$, corresponding to the time after elections for National Parliament. 